\title{
ANALISA PENGARUH HAULING DAN PURSSING KAPAL PURE SEINE DI MALUKU
}

\author{
OBED METEKOHY \\ E-mail : bobmetekohy2710@gmail.com \\ Program Studi Teknik Perkapalan, Fakultas Teknik Universitas Pattimura
}

\begin{abstract}
ABSTRAK
Kapal ikan pure seine yang beroperasi di perairan Maluku termasuk sarana perikanan tangkap yang produktif. Tetapi mempunyai banyak kelemahan karena pembuatannya secara tradisional banyak menyimpang dari syarat teknis rancang bangun kapal. Stabilitas kapal yang diharapkan dapat menjamin kontinyutas pengoperasian penangkapan pada saat hauling sering menjadi kendala sehingga operasional penangkapan harus dihentikan, untuk menghindari terjadinya resiko kecelakaan dilaut. Penelitian ini bertujuan menganalisa pengaruh stabilitas kapal dalam mengoperasikan alat tangkap pada saat hauling. Metode yang digunakan adalah metode survey terhadap ukuran pokok kapal yang sudah ada di perairan Maluku. Analisa stabilitas hauling menggunakan kriteria Stabilitas US Navy dan Metode Macchi untuk menganalisa Momen tarik alat tangkap dan hasil tangkapan. Hasil pengukuran stabilitas dinamis kapal penelitian pada saat hauling bergantung pada hasil tangkapan, semakin besar hasil tangkapan maka kemiringan kapal menjadi lebih besar, dengan hasil tangkapan 0.93 ton dan berat alat tangkap 3.237 ton membentuk sudut kemiringan sebesar $12^{\circ}$ dengan nilai $\mathrm{GZ}=0.20$ meter kemudian setelah dianalisa menurut kriteria stabilitas US Navy menunjukkan ferforma stabilitasnya sangat baik, karena sudut $\mathrm{C}<15^{\circ}$ dan nilai GZ pada saat hauling $\leq 0.30$ meter, namun kapal akan mengalami kondisi kritis sesuai hasil analisa Metode Macchi apabila momen tarik alat tangkap dan hasil tangkapnya melebihi momen tarik total maksimum yang diijinkan yaitu $>12.332$ ton.meter pada sudut kemiringan dinamis $>24^{\circ}$
\end{abstract}

Kata kunci : Stabilitas, Hauling \& Purssing Kapal Pure Seine

\section{PENDAHULUAN}

Kapal pukat cincin merupakan sarana penangkapan ikan yang sangat mendukung operasi penangkapan ikan dilaut bagi nelayannelayan di pesisir perairan Maluku. Pengoperasian alat tangkap pukat cincin dilakukan dengan cara melingkarkan jaring pada gerombolan ikan sehingga ikan yang terkurung tertangkap dan tidak dapat meloloskan diri, baik ke arah horizontal maupun kearah vertikal (Ayodhyoa,1981). Untuk memaksimalkan operasional penangkapan ikan, kapal pure seine harus mempunyai performa stabilitas yang lebih baik. Menurut Fyson, 1985 stabilitas kapal merupakan salah satu kriteria teknis yang harus dipenuhi dalam perencanaan kapal-kapal perikanan tangkap. Demikian karakteristik daerah penangkapan ikan (fishing ground) pada kondisi cuaca ekstrim haruslah dikaji secara khusus. Penyimpangan persyaratan teknis dalam desain dan pembuatan kapal, berdampak negatif bagi keselamatan kapal dan nelayan dalam operasi penangkapan ikan di laut. Laporan dari Komite Nasional Keselamatan Transportasi (KNKT) tahun 2007 - 2011 mencatat $59 \%$ kecelakaan dilaut terjadi karena faktor teknis dan $41 \%$ karena faktor manusia (human error) (KNKT,
2011). Kapal penangkap ikan pukat cincin yang beroperasi di perairan Maluku yang berpangkalan di pelabuhan pendaratan ikan Eri/Latuhalat, Laha, Hitu, Waai dan Amahai, pada umumnya proses pembuatan kapal, tidak sesuai standar rancang bangun desain teknis perkapalan, hanya dilakukan secara tradisional. Dari aspek operasional yang selama ini menjadi masalah bagi nelayan dilaut adalah proses manouver kapal, untuk mengurung dan membatasi pergerakan ikan yang akan ditangkap (setting) dan proses penarikkan alat tangkap dan hasil tangkapan (purssing \& hauling). Kondisi yang dialami nelayan di laut sering mengalami kondisi stabilitas kritis yaitu kapal mengalami sudut kemiringan melintang yang besar, akibat pengaruh beban tarik alat tangkap dan hasil tangkapan, serta melakukan manouver dalam lintasan lingkaran pada kecepatan dengan waktu yang singkat. Contoh kasus ketika kemiringan kapal semakin besar maka operasi penangkapan dihentikan.

Dari aspek desain kapal, terlihat ukuran kapa 1 sangat mempengaruhi karakteristik teknis. Jika ukuran lebar kapal kecil maka kapal akan mengalami sudut keolengan yang besar (Poehl s, 1979) Dari hasil pengamatan awal menunjuk 
an adanya keragaman dimensi dari kapal dengan alat tangkap pukat cincin yang digunakan. Selai $\mathrm{n}$ berbagai masukan dari operator kapal terkait a spek stabilitas kapal, sehingga perlu adanya suat $\mathrm{u}$ kajian tentang pengaruh stabilitas teknis kap al pure seine dalam operasi penangkapan, supay a dapat menjamin keselamatan kapal dan nelay an serta meningkatkan kontinuitas operasional pe nangkapan kapal pure seine di perairan Maluk u.

\section{KAJIAN TEORI DAN METODE}

\section{Kapal Pure Seine}

Pure seine adalah peralatan yang digunakan untuk menangkap ikan pelagis yang me mbentuk gerombolan ( Ayodhyoa, 1985 ). Kapal ikan type pure seine mempunyai prinsip penangk apan dengan cara melingkari gerombolan ikan dengan jaring. Pada bagian bawah jaring diker ucutkan dengan menarik tali kerut guna memp erkecil ruang lingkup gerak ikan, sehingga ika $\mathrm{n}$ tidak dapat meloloskan lolos dirinya, tertangk ap dan terkumpul pada kantongnya.

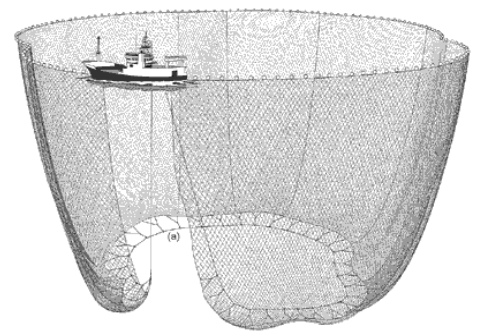

Gambar 1 Proses Penangkapan kapal pure sein e

Dalam mendesain dan membangun kapal ikan, kelaiklautan dan kenyamanan nelayan merupakan hal utama yang harus diperhatikan yaitu dengan meningkatkan kemampuan stabilitas kapalnya (N omura \& Yamazaki, 1977). Di Indonesia sebagai s tandar peraturan desain, pembuatan dan pengawa san kapal diatur dan ditentukan oleh Biro Kla sifikasi kapal Indonesia. BKI adalah badan teknik yang melakukan kegiatan dalam bidang pengawa san terhadap kapal-kapal baik yang sementara dib angun maupun untuk kapal-kapal yang sudah bero perasi (Sukarsono, 1991).

\section{Stabilitas Statis}

Stabilitas kapal adalah kemampuan kapal untuk kembali ke posisi semula setelah menjadi miring akibat bekerjanya gaya dari dalam atau pun dari luar, yang terjadi pada kapal (Hind, 1982). Stabilitas kapal terbagi dalam stabilitas statis dan stabilitas dinamis. Stabilitas statis (initial stability) adalah stabilitas kapal yang diukur pada kondisi air tenang dengan beberapa sudut keolengan pada nilai ton displacement yang berbeda. Stabilitas Dinamis adalah stabilitas kapal yang diukur dengan jalan memberikan suatu usaha pada kapal sehingga memberikan sudut keolengan tertentu. Stabilitas kapal merupakan salah satu syarat utama untuk menjamin keselamatan kapal dan kenyamanan kerja nelayan di atas kapal. Stabilitas sebuah kapal dipengaruhi oleh letak ketiga titik konsentrasi gaya yang bekerja pada kapal tersebut. Ketiga titik stabilitas kapal tersebut adalah titik B (center of buonyancy), titik $\mathrm{G}$ (center of gravity), dan titik M (metacenter).

\section{Stabilitas Kapal Saat Hauling \& Purssing}

Penangkapan ikan pelagis dengan pure seine memerlukan ketrampilan khusus, untuk mengoperasikan kapal dengan perlengkapan tangkapnya. Hal yang sering terjadi adalah kehilangan stabilitas apabila ada kombinasi arah angin, gelombang dan hasil tangkapan ikan. Kapal pure seine di perairan Maluku, umumnya mempunyai 2 konsentrasi titik tangkap yaitu pada Titik P1 dan P2 untuk melakukan hauling dan purssing.

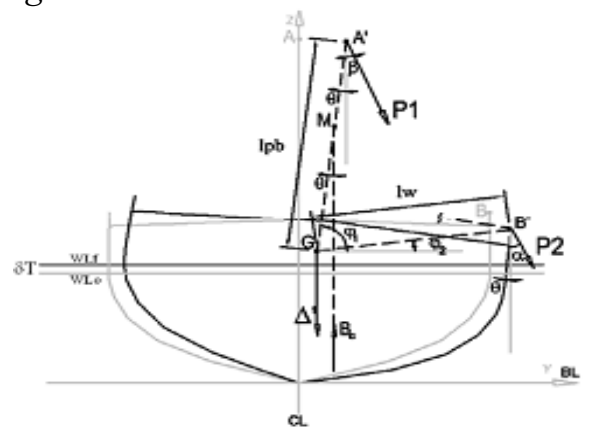

Gambar 2 Gaya gaya yang bekerja dalam mengoperasikan alat tangkap

Stabilitas kapal pada saat hauling \& purssing dinyatakan dalam skenario sederhana tentang kemiringan kapal akibat pengaruh tarikan beban alat tangkap dan hasil tangkapan yang bekerja pada titik P1 dan titik P2 serta berat nelayan yang bertumpu pada sisi kapal dalam menarik jaring diperlihatkan pada gambar 2. Prosedur untuk menghitung sudut kemiringan kapal akibat nelayan bertumpu pada sisi kapal dalam 
menarikkan alat tangkap jaring dan hasil tangkapan ikan dihitung menurut metode Macchi ( Mantari, 2010).

Untuk mengitung sudut stabilitas statis dari kapal pure seine, merupakan kisaran dari stabilitas awal dimana $\theta$ adalah sudut kemiringan kapal akibat gaya tarik alat tangkap dan hasil tangkapan dan titik $\mathrm{M}$ adalah tinggi metasenter diketahui dengan cara menghitung stabilitas antara momen kemiringan kapal dan stabilitas statis menurut persaman berikut:

$\mathrm{F} \cos \alpha \cdot 1 \cdot \cos (\phi-\theta)=(\Delta+\mathrm{F} \cos \alpha) \mathrm{GZ}$

Kemudian disederhanakan sehingga diperoleh rumus sebagai berikut :

$$
{ }_{s}=\operatorname{arctg} \frac{(\Delta+F \cos \alpha)+F \cos \alpha \cdot l}{F \cos \alpha \cdot l}
$$

Sudut kemiringan kapal yang terjadi karena pengaruh operasional alat tangkap ditunjukkan dalam persamaan sebagai berikut:

$$
\int_{0}^{\theta_{d}} F \cdot \cos \alpha \cdot l \cdot \cos (\varphi-\theta) \cdot d \theta=\int_{0}^{\theta_{d}}(\Delta+F \cdot \cos \alpha) \cdot \overline{G Z} \cdot d \theta
$$

Kemudian rumus diatas disederhanakan sebagai berikut :

$$
\theta_{S}=2 \operatorname{arcctg}\left(\frac{(\Delta+F \cdot \cos \alpha) \cdot G M+F \cos \alpha \cdot l \cdot \sin \varphi}{F \cos \alpha \cdot l \cdot \sin \varphi}\right)
$$

Selanjutnya dengan menggambungkan persamaan diatas maka diperoleh persamaan yang menyatakan kondisi kritis operasional penangkapan.

$$
\theta_{d}=2 \theta_{S}
$$

\section{METODE PENELITIAN}

\section{Lokasi Dan Waktu Penelitian}

Penelitian dilakukan di Maluku pada kapalkapal pure seine yang berpangkalan di PPI Eri, Hitu, Waai dan Amahai dilaksanakan selama 6 bulan yaitu dari bulan Mei sampai November 2017.

\section{Metode Pegumpulan Data}

Data primer dikumpulkan melalui wawancara dan pengukuran terhadap karakteristik teknis desain kapal dan alat penangkapan. Pengukuran terhadap karakteristik teknis desain kapal meliputi: LOA, LBP, LWL, B, D dan tinggi tiang penarik jaring. Data alat dan perlengkapan penangkapan yang diukur adalah panjang, tinggi dan berat jaring, jumlah dan berat nelayan, berat mesin. Pengukuran untuk membuat rencana garis, stabilitas dinamis, berat jaring, dan stabilitas statis dilakukan terhadap kapal dengan nomor sampel 21 mempunyai ukuran tonase 16 GT, berpangkalan pada pelabuhan pendaratan ikan di desa Eri Latuhalat yang melakukan operasi penangkapan ikan di periaran laut Banda Maluku. Pengukuran kapal untuk mendapatkan ukuran utama dan bentuk lambung kapal dibuat dalam tabel ordinat dengan program Exel Microsoft Office 2007 untuk membuat gambar rencana garis kapal ( lines plan), selanjutnya digambar dengan program Auto Cad Versi Classic 2007. Pengukuran kemiringan kapal menggunakan Clinometer On Protactor digital yang dipasang dirumah geladak pada bagian tengah kapal ( midship ) pada saat posisi kapal dalam kondisi berlabuh, menuju fishing ground, melakukan proses hauling \& purssing dan kembali dari fishing ground. Untuk mengetahui posisi kapal penelitian didaerah fishing ground dalam proses penangkapan pada saat hauling \& pursing ditentukan melalui GPS (Global Positioning System).

\section{HASIL DAN PEMBAHASAN}

\section{Stabilitas Dinamis Kapal \\ - Stabilitas kapal Menuju Fishing Ground}

Stabilitas dinamis adalah stabilitas kapal yang diukur pada sudut kemiringan kapal yang lebih besar karena pengaruh external dan internal akibat kondisi daerah fishing ground dan nelayan dalam mengoperasikan alat tangkap. Gambar 3 Menunjukkan kemiringan kapal pukat cincin No 21 ketika menuju daerah penangkapan berada pada posisi $3^{\circ}-15^{\circ}$ karena dipengaruhi arus, angin dan tinggi gelombang maksimum mencapai $0,5 \mathrm{~m}$. Kecepatan kapal pada saat menuju fishing ground adalah $7 \mathrm{knot}$ atau $3.598 \mathrm{~m} / \mathrm{det}$ dengan kecepatan pembalik atau waktu periode oleng kapal 4,5 detik waktu ini memenuhi standar waktu periode oleng untuk kapal- kapal ikan yaitu 4,5 -7 detik. 


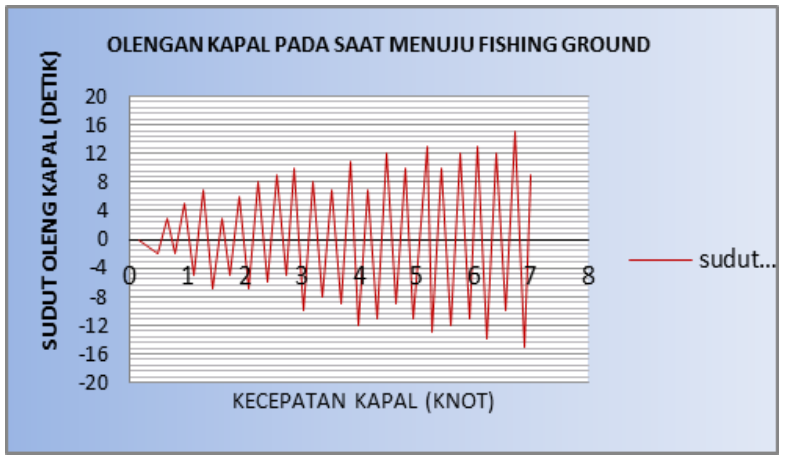

Gambar 3 Grafik Stabilitas kapal menuju fishing ground

\section{- Stabilitas Pada Saat Hauling \& Purssing}

Karakteristik stabilitas saat hauling \& purssing sangat bergantung pada kondisi fishing ground, alat tangkap, tinggi tiang hauling dan hasil tangkapan. Apabila tinggi tiang hauling, ukuran alat tangkap dan hasil tangkapan yang lebih banyak/besar maka tegangan tarik semakin besar dalam menarik alat tangkap dan hasil tangkapan dari dalam air, semuanya ini sangat mempengaruhi stabilitas kapal pada saat phauling \& purssing.

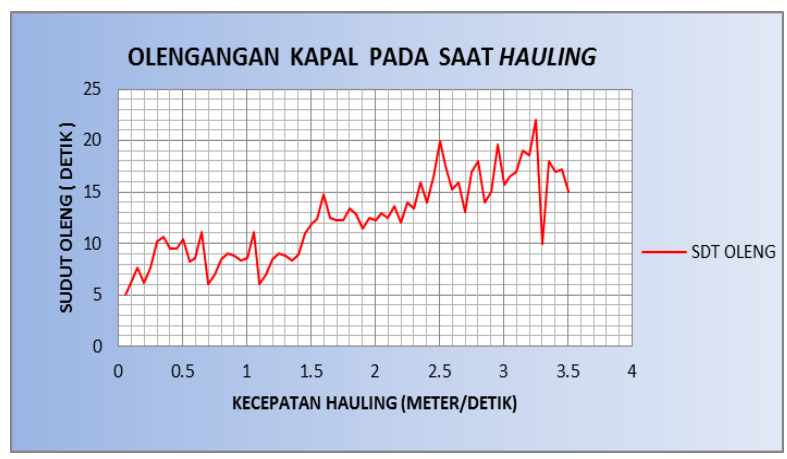

Gambar 4 Grafik stabilitas kapal pada saat hauling \& purssing

Gambar 4 menunjukkan kapal pukat cincin No 21 memiliki kecepatan pembalik sebesar 8 detik dan semakin besar sehingga kapal terus mengalami kemiringan sampai pada sudut kemiringan maksimum sebesar $22^{\circ}$, karena pengaruh gaya gaya yang bekerja pada sisi kanan kapal karena tarikkan jaring dan hasil tangkapan oleh nelayan ( P1) dan pengaruh tarikan tali ris dan tali kerut yang dipasang pada kedua titik tiang jaring power blok/katrol (P2) yang ditarik oleh nelayan untuk mengkerucutkan serta menutup bagian bawah jaring guna mengurung ikan yang akan di tangkap.

Dari hasil pengukuran diketahui pada saat hauling mempunyai kecepatan tarik $0.35 \mathrm{~m} / \mathrm{det}$ dengan selang waktu 20 menit mempunyai sudut hauling dan purssing maksimum adalah $22^{\circ}$, menunjukkan kapal pada saat hauling dan purssing masih stabil, karena masih jauh berada pada kedudukan titik GMo $=0.77$ meter, dan tinggi lengan balik maksimum statis sebesar 0.50 meter. Posisi GZ maksimum pada saat hauling dan pursing adalah sebesar 0.20 meter dengan sudut kemiringannya $\theta s=12^{\circ}$. Hasil pada titik C yang menunjukkan titik perpotongan antara grafik GZb dengan grafik GZ dalam gambar diagram stabilitas adalah $14^{\circ}$ nilai kemiringan sudut hauling\& purssing ini telah memenuhi standar Stabilitas Kapal Angkatan Laut Amerika (US.Navy).

\section{- Stabilitas Pengaruh Beban Tarik Saat Purssing \& Hauling}

Beban tarik alat tangkap dan hasil tangkapan pada kondisi normal dan kritis sangat berpengaruh terhadap kemiringan kapal pada saat purssing. Hasil analisa pada kondisi stabilitas normal dan kritis pada saat purssing dari nilai $R^{2}=0.9904$ menunjukkan pengaruh beban tarik hasil tangkapan terhadap kemiringan kapal pada kedua kondisi stabilitas saat purssing adalah $99 \%$ mempunyai hubungan sangat erat, karena nilai $R^{2}$ semakin mendekati 1 .

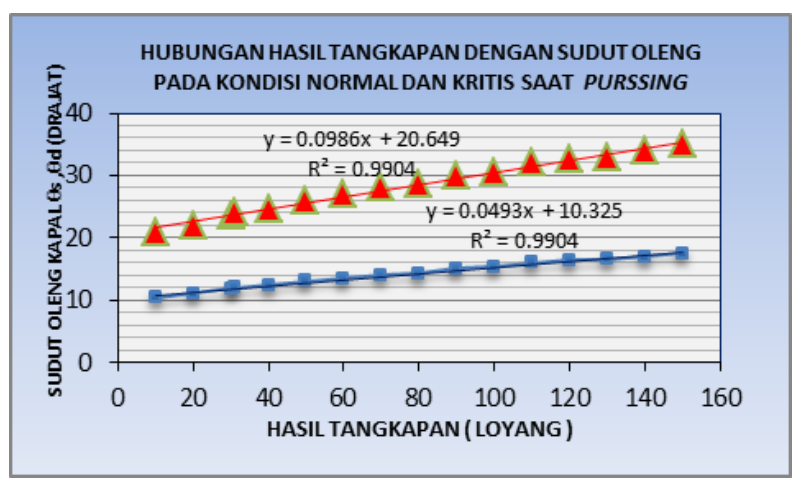

Gambar 5 Grafik stabilitas normal dan kritis pada saat purssing.

Gambar 5 menunjukkan bahwa pengaruh beban tarik alat tangkap dan hasil tangkapan pada saat purssing terhadap sudut kemiringan kapal pukat cincin No 12 pada kondisi stabilitas statis atau 
normal dan stabilitas dinamis atau kritis berbentuk kurva dengan persamaan regresi $\mathrm{y}=0.049 \mathrm{x}+$ 10.32 dan $y=0.098 x+20.64$ dimana kemiringan kapal pada kondisi normal berada pada sudut kemiringan $\theta \mathrm{s}=10^{\circ}-17.5^{\circ}$ dan kondisi dinamis/kritis kapal pada sudut oleng $\theta \mathrm{d}=20-$ $35^{\circ}$ dengan posisi hasil tangkapan sebesar $0.3-$ 4.5 ton, dan beban tarikkan alat tangkap dan hasil tangkapan sebesar $3.153-7.353$ ton. Pada saat hauling dengan beban tarik alat tangkap jarring $100 \%$ yaitu $3237 \mathrm{~kg}$ sudut olengnya $\theta \mathrm{s}=5-9^{\circ}$ dan $\theta \mathrm{d}=10-18^{\circ}$.

Hasil pengukuran sudut kemiringan kapal pada saat operasi penangkapan ikan kapal pure seine nomor 12 diperairan Maluku diketahui jumlah hasil tangkapan maksimum pada saat penelitian adalah $930 \mathrm{~kg}=0.930$ ton. Dengan berat hasil tangkapan tersebut ditambah berat alat tangkap sebesar $\mathrm{kg} \quad 2.853$ ton maka diperoleh beban tarik alat tangkap dan hasil tangkapan adalah 3.783 ton.

Hasil pengukuran kemiringan kapal dengan menggunakan Clinometer On Protection digital diketahui besarnya sudut kemiringan kapal pada saat operasi penangkap dalam proses hauling dan purssing adalah $5-22^{\circ}$.

\section{- Stabilitas kapal Kembali Dari Fishing Ground}

Stabilitas dinamis kapal setelah kembali dari fishing ground tidak mempengaruhi kondisi stabilatas kapal karena pengaruh tinggi gelombang hanya $0.3 \mathrm{~m}$, lebih kecil 0,2 meter dibandingkan pada saat menuju ke fishing ground.

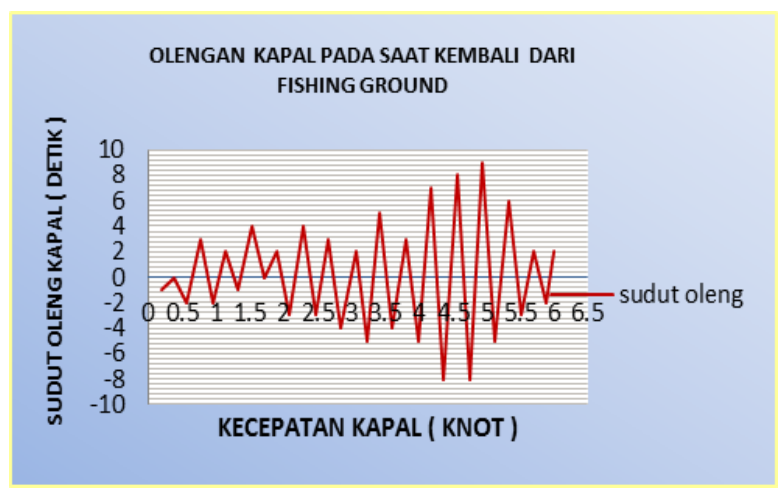

Gambar 6. Grafik stabilitas pada saat kembali dari fishing ground

Gambar 6 Menunjukkan kapal pure seine nomor 12 mempunyai sudut kemiringan $2^{\circ}-8^{\circ}$ posisi masih dalam kondisi aman. Kecepatan kapal pada saat kembali dari fishing ground adalah 6 knot atau $3.084 \mathrm{~m} /$ det dengan kecepatan pembalik 5.7 detik, waktu ini memenuhi periode oleng untuk kapal ikan yaitu 4,5 -7 detik. Kecepatan kapal pada saat kembali dari fishing ground dengan membawa tambahan hasil tangkapan sebanyak 31 loyang atau $930 \mathrm{~kg}$ mempunyai kecepatan kapal lebih kecil 1 knot dan waktu periode olengnya lebih lambat 0.2 detik dibandingkan dengan kondisi kapal pada saat menuju ke daerah fishing ground.

\subsection{Kesimpulan}

Dari hasil penelitian ini dapat disimpulkan sebagai berikut :

1. Karakteristik kapal 16 GT ini menunujukakan stabilitas awal atau stabilitas statis kapalnya baik setelah melalui pengujian stabilitas berdasarkan kriteria stabilitas kapal ikan menurut (IMO,2008) dimana luas dibawah kurva :

GZ $0-30^{\circ}=0.148$ m.rad; GZ $0-40^{\circ}=0.231$ m.rad; GZ $30-40^{\circ}=0.08$ m.rad ; GZ $>30^{\circ}=$ $0.36 \mathrm{~m}$; GZmax pada sudut $30^{\circ}=33^{\circ}$ dan $\mathrm{GMo}=0.77 \mathrm{~m}$.

2. Stabilitas dinamis kapal pure seine pada saat operasi penangkapan ikan diperairan Maluku banyak dipengaruhi karakteristik teknis desain kapal dan kondisi fishing ground (angin,arus, gelombang, dan operasional alat tangkap pada saat hauling dan purssing

3. Stabilitas saat hauling dan purssing sangat bergantung pada karakteristik kapal dan hasil tangkapan, dimana semakin besar hasil tangkapan menunjukkan beban tarik alat tangkap dan hasil tangkapan semakin besar dan memberikan dampak pada besarnya sudut kemiringan kapal. Kondisi stabilitas kritis kapal berada pada sudut $>24^{\circ}$.

\section{DAFTAR PUSTAKA}

Ayodhyoa, 1985. Suatu Pengenalan Fishing Gea $r$. Fakultas Perikanan. IPB. Bogor.

Ayodhyoa, 1972. Fishing Boat Correspondece Cource Center. Fakultas Perikanan. PB.Bogor

Bhattacharya.R.1978. Dynamic of Marine Vichcle John Wiley and Son, inc. New 
Biro Klasifikasi Indonesia, 2004. Rules for the Cl assification and Construction of Seagoing

Departemen Kelautan Dan Perikanan RI, 2009 Un dang Unadang Nomor 31 Tahun 2009 Ten tang Jenis Kapal Perikanan .Jakarta

Derret.D.R. 2006 Ship Stability for Master And Mates. Sixth Edition, Revised. Barras Ltd. Lo ndon.

Dohri, M dan Soejana. S.A. 1983. Kecakapan Bah ari, Departemen Pendidikan \& Kebudayaan J akarta.

Fridman. A.L. 2010. Calculation Fishing Gear De sign. FAO.United Nations. Fishing New Books Ltd Englands (pp 241) hal 48 -55

Fyson, J.1985. Design of Small Fishing Vessels. FAO United Nations. Fishing New book Ltd. Englands ( pp 320) hal 155 - 172

Hardjanto.2010. Pengaruh Kelebihan Dan Perges eran Muatan Di Atas Kapal Terhadap Stabilitas Kapal. Jurnal Pelayaran Dan Kepel abuhanan, Volume 1 No 1 Jakarta

Hind.A.1982. Stability And Trim Of Fishing Ve ssels. Second Edition Fishing News books Ltd. London.

House.D.J. 2005. Cargo Work For Marine Operation. Elsevier Butterworth Heinemann. London

IMO, International Maritime Organization.2008 Code On Intact Stability For All Type Ship Covered By IMO Instrument Resolutio A.649(18).

Komisi Nasional Keselamatan Transportasi, 2 011. Kajian Analisa Trend Kecelakaan T ranportasi Laut Tahun 2003 -2008. KNKT J akarta.

Smith-Munro.R.1980. Merchant Ship Design. The University.Of Liverpool Hutchinson. London

Nomura,M and Yamazaki,T. 1977. Fishing T echniques. Japan International Agency Toky o. Lecture Partly And Repated At Makasar A nd Ambon

Semyonov-Tyan-Sansky. 1980. Static And Dynam ics of Ship. Peace Publisher Moscow.
Rawson,K.J. and E.C. Tupper, 2001. Basic Ship

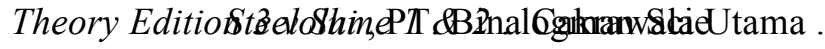
ntific and Technical London.

Sismadi, 2006. Analisis Efisiensi Penggunaan Inp ut Alat Tangkap Pure Seine Di Kota Pekalon gan.Tesis Undip. Semarang

Subroto,M.A. 2000. Teknik Kapal Penangkap Depertemen P \& K Jakarta.

Soekarsono, N.A.1991. Konstruksi Bangunan Kap al. Fakultas Teknologi Kelautan Universita D harma Persada. Jakarta.

Traung.J.O. 1975. Fishing Boat of the Word, 2. Published by Fishing News Britain - Londo n. 